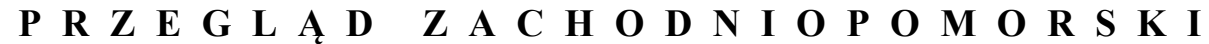 ROCZNIK XXXV (LXIV) ROK 2020 ZESZYT 2
}

\section{$\begin{array}{lllllllll}\mathbf{A} & \mathbf{R} & \mathbf{T} & \mathbf{Y} & \mathbf{K} & \mathbf{U} & \mathbf{L} & \mathbf{Y}\end{array}$}

\author{
PAWE⿺ Gut \\ https://orcid.org/0000-0003-3148-3298 \\ Akademia Pomorska w Słupsku \\ pawel_gut@wp.pl
}

\section{Kuratorium GimnazJUm AKADEMicKiego w SzCZECINIE 1667-1805}

Słowa kluczowe: Gimnazjum Karolińskie, Gimnazjum Akademickie, Gimnazjum Mariackie, kuratorium, Szczecin, Pomorze, szkolnictwo, Fundacja Mariacka

Keywords: Carolingian Gymnasium, Academic Gymnasium, Marian Gymnasium, schoolboard, Szczecin, Pomerania, education, Marian Foundation

Szkolnictwo akademickie w Szczecinie w czasach nowożytnych reprezentowane było przez Pedagogium Książęce (Fürstliches Pedagogium), a następnie Gimnazjum Karolińskie (Gimnasium Carolinum) ${ }^{1}$. Oba te zakłady kształcenia powstały jako fundacje monarsze $(1543,1667)$, a podstawą ich utrzymania był majątek

1 Dziejom Pedagogium Książęcego i Gimanazjum Karolińskiego w Szczecinie poświęcono kilka monografii, zob. Karl Friedrich Wilhelm Hasselbach, Der Geschichte des ehemaligen hiesigen Pädagogium, nachherigen K. Gymnasium (Stettin, 1844), 1-40; Martin Wehrmann, „Geschichte des Marienstifts-Gymnasiums 1544-1894”, w: Festschrift zum dreihundertfünfzigjährigen Jubiläum des Königlichen Marienstifts-Gymnasiums zu Stettin am 24. und 25. September 1894 (Stettin, 1894); Sylwia Wesołowska, „Das Fürstliche Pedagogium bzw. Gymnasium Carolinum in Stettin”, w: Die Universität Greifswald in der Bildungslandschaft des Ostseeraums, red. Dirk Alvermann, Nils Jörn, Jens E. Olesen (Berlin, 2007), 105-122. Ostatnio dzieje obu szkół przedstawili Radosław Gaziński i Paweł Gut w monografii poświęconej szkolnictwu wyższemu w Szczecinie, zob. Radosław Gaziński, „Pedagogium Książęce (lata 1544-1667)”, w: Akademicki Szczecin XVI-XXI wiek, red. Piotr Niedzielski, Waldemar Tarczyński (Szczecin, 2016), 15-46; Paweł Gut, „Szczecińskie akademickie szkoły średnie w II połowie XVII i XVIII wieku”, w: Akademicki Szczecin XVI-XXI wiek, red. Piotr Niedzielski, Waldemar Tarczyński (Szczecin, 2016), 47-80. 
sekularyzowanej Kapituły Kościoła Mariackiego w Szczecinie, który stał się podstawą powołanej w 1541 roku Fundacji Mariackiej (Marienstift)2.

Podstawą działania każdej z wymienionych szkół były przepisy statutów, ustalone przez fundatorów. Regulowały one organizację szkół, skład grona profesorskiego, zakres kształcenia czy majątek placówek. Istotne miejsce zajmowały także przepisy o sposobie zarządzania oraz nadzoru nad szkołami i majątkiem fundacji.

Podstawą działania Pedagogium była umowa zawarta w Jasienicy - 25 października 1543 roku - między książętami pomorskimi Barnimem IX Starym a jego bratankiem Filipem I ${ }^{3}$. Obaj władcy dla sprawowania władzy i nadzoru nad Pedagogium, a także bursą studencką, powołali etliche Curatores - pierwszymi zostali radcy książęcy: Jobst von Dewitz, Jacob von Wobeser, Niclaus Brunon oraz Petrus Pritzen. Ponadto, na wypadek, gdyby kuratorzy nie mogli pełnić swoich funkcji (śmieré, choroba, praca), książęta wyznaczyli drugi skład kuratorium w osobach Bartolomeusa Schwänena zarządcy domeny w Bytowie, Clausa von Puttkammera, zarządcy domeny w Szczecinie, Balthasara von Woldego, kanclerza księcia Filipa I oraz Moritza von Damitza, zarządcy domeny z Ueckermünde ${ }^{4}$.

Szkoła powołana przez pomorskich władców w ciągu ponad stu lat działania była znaczącą placówką kształcenia młodzieży, a także miejscem prowadzenia badań naukowych. Jednak wydarzenia wojny trzydziestoletniej, rozbiór Pomorza między Szwecję i Brandenburgię (1648/1653), oblężenie Szczecina w 1659 roku, nie wpłynęły pozytywnie na stan Pedagogium. Uczelnia pogrążyła się w kryzysie, pomimo zabiegów rektora Johannesa Micraeliusa (rektor 16421658), a także władców szwedzkich, nowych protektorów Pedagogium Książęcego w Szczecinie, które objęły działalność szkoły (kadra, liczba studiujących, dyscyplina studentów) i jej podstawy finansowe, czyli majątek Fundacji Mariackiej $^{5}$. Król Karol XI polecił namiestnikowi prowincji pomorskiej i marszałkowi Carlowi Gustavowi Wranglowi przeprowadzić wizytację Pedagogium w 1666 roku. Sprawozdanie komisji potwierdziło naganny stan uczelni. Jednym z wnio-

2 Gaziński, „Pedagogium”, 18.

3 Wehrmann, ,Geschichte”, 11-14.

${ }^{4}$ Archiwum Państwowe w Szczecinie (dalej: APS), Fundacja Najświętszej Marii Panny (dalej: FNMP), sygn. 1441, k. 2.

5 Wehrmann, „Geschichte”, 62, 64-65, 75; Bogdan Wachowiak, „Szczecin w okresie przewagi państwa feudalnego (1478-1713)”, w: Dzieje Szczecina, red. Gerard Labuda, t. 2: Wiek X-1805 (Poznań, 1985), 433. 
sków wizytatorów była likwidacja dotychczasowej placówki i w jej miejsce powołanie nowej uczelni ${ }^{6}$. Działalność wizytatorów i kuratorów w 1666 i 1667 roku kosztowała 782 floreny?

Za wstawiennictwem Davida Meviusa, wybitnego prawnika i polityka pomorskiego, wiceprezydenta Trybunału w Wismarze, władze szwedzkie postanowiły powołać nową placówkę. Na początku 1667 roku Pedagogium rozwiązano i zdecydowano o powołaniu szkoły o charakterze akademickim - Regium Gymnasium Carolinum. Uroczyste otwarcie nowej uczelni w Szczecinie nastąpiło 24 listopada 1667 roku$^{8}$.

Podstawy organizacyjne placówki, a także sposób jej finansowania i zarządzania określono w przepisach statutu (Verfassung) wydanego 18 października 1667 roku w Wołogoszczy (Wolgast) przez namiestnika Carla Gustava Wrangla9. Finansowanie gimnazjum akademickiego odbywać się miało nadal z dochodów zreformowanej Fundacji Mariackiej i służyć utrzymaniu kościoła Mariackiego i zabudowań szkoły, a także profesury i uczniów (Verfassung, Cap. IX). Ponadto szkoła odziedziczyła po Pedagogium siedzibę, czyli budynki w kompleksie kościoła Mariackiego, który stał się również świątynią uczelni ${ }^{10}$.

Zgodnie ze statutem w imieniu fundatora, króla Szwecji Karola XI, nadzór nad fundacją, a także uczelnią sparowało Kuratorium (Verfassung, Cap. X Von

6 Johann Carl Conrad Oelrichs, „Gewechselte Schriften verschiedener grosser Männer vor und wider die ehemahls vorgewesene Verlegung der Universität Greifswald nach Stettin 1666", w: tegoż, Historisch-Diplomatische Beyträge zur litterarischen Geschichte fürnehmblich des Hertzogthums Pommern, cz. 2 (Berlin, 1790), 19-31; Wehrmann, „Geschichte”, 52-53; Wachowiak, „Szczecin”, 433; Zofia Mielcarek, Bolesław Owczarek, Od Pedagogium do Uniwersytetu Szczecińskiego (Szczecin, 1985), 61-63; Gut, „Szczecińskie”, 47-48.

7 APS, FNMP, sygn. 1441, k. 1-5.

8 Acta Inaugurationis Gymnasii Carolini (Stetini, 1667-1668), passim. Również: APS, Rękopisy i Spuścizny, sygn. 788. Uroczyste kazanie wygłosił dr Joachim Fabricius, generalny superintendent oraz profesor Pedagogium i gimnazjum, pastor (proboszcz) kościoła Mariackiego w Szczecinie. Fons Sapeientiae, Stetini in Gymnasio Carolino ex Dei Gratia Reclusus, Der Weissheit Bruss zu Stettin im Carolinischen Gymnasio auss Gottes Gnade wider eröfnet (Stettin, 1668), 1-48; Mielcarek, Owczarek, Od Pedagogium, 63; Wesołowska, „Das Fürstliche”, 119-120; Gut, „Szczecińskie”, 49.

9 „Verfassung des Gymnasii Carolini zu Alt. Stettin”, w: Acta Inaugurationis Gymnasii Carolini, 1-20. Statut gimnazjum składał się z 11 rozdziałów.

${ }^{10} \mathrm{Na}$ temat budynku kościoła Mariackiego, zabudowań szkolnych Pedagogium Książęcego i Gimnazjum Karolińskiego (od 1716 r. - Akademickiego), a także majątku fundacji zob. Carl Fredrich, „Die ehemalige Marienkirche in Stettin und ihr Besitz”, cz. 1: Baltische Studien 21 (1918), 143-246; cz. 2: Baltische Studien 23 (1920), 3-60 (o pomieszczeniach szkoły, s. 27-43; o majątkach ziemskich fundacji, s. 56-60). 
der Curatoren Person und Ambte), co było nawiązaniem do wspomnianej wyżej umowy książęcej z 1543 roku. Dodatkowo w statucie z 1667 roku znalazł się zapis, że ustanowienie kuratorium dla fundacji i szkoły podnosi jej prestiż, gdyż organ ten jest stosowany przy administrowaniu uniwersytetami i szkołami prowincjonalnymi (Gleichwie insgemein bey den Universitäten und den Provinzial Schulen gewisse Curatores zu seyn pflegen, denen die inspection über solche Collegia anvertrawet ist).

Kuratorium składało się z czterech członków - dwóch reprezentujących króla Szwecji oraz dwóch występujących w imieniu pomorskich stanów. Królewskimi przedstawicielami byli kanclerz (Kanzler) oraz jeden z radców rejencji (Regierungsrat), czyli urzędnicy najwyższego organu królewskiego administrującego Pomorzem Szwedzkim. Z kolei stany reprezentować mieli dwaj uczeni i dzielni mężowie (gelehrte und tapffere Männer), których miał wybierać sejm prowincjonalny, a zatwierdzać wspomniana rejencja. Ten ostatni urząd przyjmował również od nich przysięgę na wierność królowi.

Kuratorzy wybrani w 1667 roku zostali zobowiązani w pierwszej kolejności do sprawdzenia dotychczasowego stanu fundacji i jej finansowych podstaw. Według statutu kuratorium stanowiło organ zarządzający i nadzorujący szkołą, fundacją i kościołem Mariackim w Szczecinie, a także profesorami i uczniami oraz urzędnikami wspomnianych instytucji. Kuratorzy dbali o finanse fundacji, jej dochody i wydatki - ustalali pensje, deputaty dla profesorów i urzędników, stypendia dla studentów - o zabudowania należące do fundacji i szkoły, także o świątynię - kościół Mariacki.

Do zadań kuratorium należało sprawdzanie i opiniowanie kandydatów na profesorów gimnazjum oraz pastorów kościoła Mariackiego, a następnie przedstawianie najlepszej kandydatury do zatwierdzenia i nominowania przez Królewską Rejencję. Kuratorzy, za zgodą rejencji, decydowali również o wynagrodzeniu powołanego nauczyciela i odbierali od niego przysięgę. Poza tym co cztery lata nauczyciele deklarowali przed kuratorium chęć dalszej pracy w szkole lub składali rezygnację z etatu (Verfassung, Cap. IV, X) ${ }^{11}$. Proces powoływania nauczycieli do gimnazjum odbywał się na podstawie specjalnej instrukcji, którą dołączono do statutu ${ }^{12}$.

\footnotetext{
${ }^{11}$ Nauczyciel, który chciał zakończyć pracę w szkole lub też ją kontynuować przez kolejne 4 lata, musiał to zgłosić w terminie 6 miesięcy przed upływem terminu kadencji.

${ }^{12}$ Brevis instructio: Ex qva consensu Dnn. Curatorum, Gimnasii Carolini professors in docendi nunere versabuntur.
} 
Zadaniem kuratorium było również czuwanie nad programem studiów w gimnazjum i systemem kształcenia (Verfassung, Cap. X) ${ }^{13}$. Odpowiadało ono również za wyznaczanie deputatów drewna, produktów spożywczych i innych przedmiotów przeznaczonych dla uczniów, służących zapewnieniu bezpieczeństwa sanitarnego, ogrzewaniu budynków szkoły i bursy (Verfassung, Cap. VII).

Kuratorzy uczestniczyli także $\mathrm{w}$ procesie utrzymania dyscypliny wśród uczniów, mieli także rozstrzygać w sporach między kadrą profesorską i uczniami, a także środowiskiem zewnętrznym (mieszczanie, garnizon). Kuratorium wspólnie $\mathrm{z}$ profesorami mogło prowadzić postępowania dyscyplinarne i wymierzać kary, jednak za wiedzą władz prowincji (Verfassung, Cap. VIII, X) ${ }^{14}$.

Kuratorium odpowiadało za cały majątek ruchomy i nieruchomy fundacji i szkoły, dobra ziemskie, poddanych, prawidłową gospodarkę wspomnianym majątkiem i otrzymywanymi z niego dochodami, które przeznaczano na utrzymanie kościoła Mariackiego i uczelni oraz jej profesorów i uczniów. Kuratorzy sprawowali władzę nadzorczą nad administratorem fundacji, który zarządzał bezpośrednio jej majątkiem, kontrolowali jego działalność, m.in. przyjmując rokrocznie na św. Michała rejestry i rachunki (Verfassung, Cap. IX, X) ${ }^{15}$.

Zadania swoje wykonywali poprzez periodyczną kontrolę dokumentów przedkładanych przez rektora gimnazjum i administratora fundacji, a także wizytacje zwyczajne i nadzwyczajne szkoły. Obowiązkiem kuratorium było niezwłoczne likwidowanie i rozwiązywanie wszystkich wykrytych niedomagań czy błędów (Verfassung, Cap. X).

Wspomniane wizytacje zwyczajne miały odbywać się co roku, w każdy poniedziałek po niedzieli św. Trójcy (Montag nach Trinitatis). Prócz członków kuratorium do grona wizytatorów należeli również superintendent pomorski i trzej reprezentanci stanów prowincji, po jednym ze stanu prałatów, miast oraz szlachty (Verfassung, Cap. XI). Z kolei wizytacje nadzwyczajne miały być

${ }^{13}$ Jednym z zadań kuratorium było stanie na straży ortodoksyjności kształcenia teologicznego i religijnego w szkole, zgodnie z wyznaniem ewangelicko-augsburskim, przeciwdziałanie wpływom kalwinizmu lub katolicyzmu.

${ }^{14}$ Dla rozstrzygania problemów spornych między studentami a mieszczanami i profesorami utworzono sąd rozjemczy (Schiedsgericht), który składał się z dwóch kuratorów, administratora fundacji, trzech profesorów, rektora szkoły radzieckiej (Ratschule), a także proboszcza kościoła św. Jakuba, zob. Wehrmann, „Geschichte”, 82.

${ }^{15}$ Kuratorium wskazywało kandydata na administratora fundacji - po prezentacji przed rejencją i zatwierdzeniu, przyjmowali od niego przysięgę, przekazywali dokumentację potrzebną do administrowania fundacją i jej majątkiem. 
wszczynane na wyraźne sygnały o złym stanie fundacji i uczelni. W ciągu panowania szwedzkiego, mimo powtarzających się problemów z utrzymaniem szkoły, liczbą uczniów itp. taka wizytacja miała miejsce tylko raz w 1703 roku $^{16}$.

W 1667 roku reprezentantami króla w kuratorium zostali kanclerz Heinrich Cölestin von Sternbach oraz radca Thun. Z kolei kuratorami stanowymi byli właściciel Skarbimierzyc (Sparrenfelde) i Wąwelnicy (Wamlitz) Aleksander Ernest von Eichstädt, a także landrat Caspar Detlef von Wulffen ${ }^{17}$. Przedstawiciele królewscy w kuratorium fundacji i gimnazjum zmieniali się wraz ze zmianami personalnymi we władzach prowincjonalnych. Przez kilkanaście lat jednym z kuratorów był radca rejencji Berend Christoph Jägern. Po jego śmierci w 1707 roku stanowisko to zajął starosta zamkowy ze Szczecina Martin Klinkenström ${ }^{18}$. Z kolei we wspomnianej wyżej wizytacji w 1703 roku brali udział prócz wymienionego już radcy Jägerna również szlacheccy kuratorzy - landrat Friedrich Wilhelm von Eickstedt i komisarz dystryktu anklamskiego Friedrich von Flemming, a także generalny superintendent i wicekanclerz greifswaldzkiego uniwersytetu prof. Johann Friedrich Meyern ${ }^{19}$.

W 1713 roku, w toku trzeciej wojny północnej (1700-1720), Szczecin został zajęty przez Prusy. Nowy władca Szczecina król Prus Fryderyk Wilhelm I zainteresował się problemami działającego w mieście gimnazjum już w 1715 roku, choć nie posiadał on jeszcze formalnych praw do miasta i szkoły. Te ostatnie nabył dopiero za sprawą traktatu pokojowego podpisanego w Sztokholmie 21 stycznia 1720 roku, choć już od 1715 roku bezwzględnie wprowadzał pruski porządek w zdobytym podstępem Szczecinie i Pomorzu Nadodrzańskim ${ }^{20}$.

Pierwszą decyzją nowego patrona szkoły było ustanowienie składu kuratorium (23 czerwca $1715 \mathrm{r}$ ). W pismach królewskich odwołano się do statutu z 1543 roku, jednak formalnie nadal podstawą działania uczelni, fundacji, a także ustanowionego dla nich kuratorium były przepisy z 1667 roku. Utrzymano

${ }^{16}$ Zarządzenie wizytacji wynikało ponownie ze złego funkcjonowania fundacji, a także z problemów dydaktycznych i wychowawczych w gimnazjum. Ponadto władze szwedzkie, nakazując wizytację szczecińskiego gimnazjum akademickiego, rozważały na nowo propozycję połączenia tej szkoły z greifswaldzkim uniwersytetem. APS, Gimnazjum Mariackie (dalej: GM), sygn. 4 (reces wizytacji 6 grudnia 1703 roku); Wehrmann, „Geschichte”, 88.

${ }^{17}$ APS, FNMP, sygn. 1440, k. 1-3.

${ }^{18}$ APS, GM, sygn. 6.

${ }^{19}$ Wehrmann, „Geschichte”, 88.

${ }^{20}$ Jerzy Wiśniewski, „Początki układu kapitalistycznego 1713-1805”, w: Dzieje Szczecina, red. Gerard Labuda, t. 2: Wiek X-1805 (Poznań, 1985), 450-455. 
m.in. nazwę szkoły - Gimnasium Carolinum zu Stettin, co potwierdzają dokumenty z początku XIX wieku ${ }^{21}$. Pierwszymi pruskimi kuratorami zostali dwaj reprezentanci pomorskiej szlachty, landraci von Borck oraz von Wedel, a przedstawicielami króla - radcy M.D. von Laurens i von Suckow, urzędnicy Rejencji Pomorskiej w Stargardzie (Pommersche Regierung)22. Jednocześnie, dla dokładniejszej kontroli szkoły i fundacji, król Fryderyk Wilhelm I powołał Wyższe Kuratorium (Oberkuratorium) w osobie prezydenta rejencji (Cheffpräsident) Kaspara Wilhelma von Massowa, a następnie kanclerza Filipa Ottona von Grumbkowa (Primarium und ersteren Kurator), tego ostatniego w 1742 roku odsunął jednak od wszelkich obowiązków, w tym również kierowania sprawami fundacji. Kolejnymi nadkuratorami byli prezydent kamery Georg Wilhelm von Aschersleben, a następnie Georg Christoph von Wachholtz ${ }^{23}$. Stan ten trwał aż do lat siedemdziesiątych XVIII wieku. Według Martina Wehrmanna funkcję Najwyższego Kuratorium przejął w 1777 roku Departament Duchowy w Berlinie, jednak jeszcze w 1778 roku prezydent rejencji Johann Arnold von Wyckersloth był tytułowany pierwszym kuratorem (Erster Curatel) ${ }^{24}$.

Reprezentantami władz królewskich w kuratorium byli członkowie rejen$\mathrm{cji}^{25}$. Do czasu likwidacji nadkuratorium zwykle pierwszym kuratorem w czteroosobowym kolegium był wiceprezydent rejencji, a drugim jeden z radców. W 1747 toku wiceprezydentem zasiadającym w kuratorium był Karl Joseph von Dewitz, a w 1764 roku Gustav Heinrich von Enckevort, czy w 1777 roku Julius Eberhard von Massow ${ }^{26}$. Po przejęciu funkcji nadkuratorium przez władze w Berlinie ustalono, że kierownik rejencji oraz jego zastępca będą pełnić funkcje obu członków kuratorium fundacji i gimnazjum, reprezentujących monarchę.

\footnotetext{
${ }^{21}$ APS, FNMP, sygn. 1441, k. 160.

${ }^{22}$ APS, FNMP, sygn. 1441, k. 1-9; Wehrmann, „Geschichte”, 103.

${ }^{23}$ APS, FNMP, sygn. 1441, k. 3-10; Wiśniewski, „Początki”, 543; Dariusz Łukasiewicz, „Państwo brandenbursko-pruskie wobec szkolnictwa na Pomorzu Zachodnim w latach 1648-1806", w: Szlachta - społeczeństwo - państwo między Warmia a Rugia w XVIII-XIX wieku, red. Mieczysław Jaroszewicz, Włodzimierz Stępiński (Szczecin, 1998), 160-161; Dariusz Łukasiewicz, „Reformy szkolnictwa na Pomorzu Zachodnim w XVIII w.", Przegląd Historyczny 87 (1996), 3: 517.

${ }^{24}$ Wehrmann, „Geschichte”, 102; APS, FNMP, sygn. 1441, k. 5-31.

${ }^{25}$ Urząd ten w XVIII wieku miał wszystkie kompetencje sądu najwyższego dla prowincji pomorskiej, także sprawy zwierzchności państwowej (Landeshoheit) oraz lennej (Lehnshoheit). Rejencja zajmowała się także problematyką kościelną i szkolną, pozostając w unii personalnej z konsystorzem odpowiedzialnym za te zagadnienia. Zygmunt Szultka, „Ukształtowanie się systemu absolutnego i jego kryzys”, w: Historia Pomorza, red. Gerard Labuda, t. 2: cz. 3 (Poznań, 2003), 821-830.
}

${ }^{26}$ APS, FNMP, sygn. 1441, k. 31-119. 
W 1804 roku pierwszym kuratorem był prezydent Georg Friedrich von Eickstedt, a drugim wiceprezydent Leopold von der Osten ${ }^{27}$.

Z kolei delegaci szlacheccy wybierani byli przez stany Pomorza Przedniego (Vorpommern), a także Pomorza Tylnego (Hinterpommern). $Z$ reguły były to osoby sprawujące również inne funkcje czy stanowiska w hierarchii stanowej czy instytucjonalnej. Często wybieranymi osobami byli landraci, a także, szczególnie w II połowie XVIII wieku, dyrektorzy krajowi (Landesdirektor). Ten ostatni pełnił też rolę pierwszego kuratora stanowego. Tak było w 1789 roku z Carlem von Massowem, który zastąpił dyrektora krajowego von Glasenappa, będącego w kuratorium od 1742 roku $^{28}$.

W latach czterdziestych XVIII wieku jednym z dwóch stanowych kuratorów był fizyk doświadczalny i odkrywca kondensatora (butelka Kleista) Ewald Jürgen Georg von Kleist, dziekan kapituły katedralnej w Kamieniu Pomorskim, a w latach 1747-1748 prezydent Sądu Nadwornego w Koszalinie (Hofgericht Köslin) ${ }^{29}$. Z kolei w 1778 roku kuratorem szlacheckim był kolejny z dziekanów kamieńskich, von Plathen ${ }^{30}$.

Rejencja akceptowała wybór delegatów szlacheckich do kuratorium gimnazjum i fundacji. Jednak ostateczną decyzję o nominacjach na kuratorów stanowych, jak też potwierdzenie delegacji reprezentantów królewskich podejmowały władze w Berlinie ${ }^{31}$. Generalnie praca kuratorów była honorowa w nadzorowaniu Fundacji Mariackiej i Gimnazjum Akademickiego. Jednak w II połowie XVIII wieku za pracę na rzecz zakładu naukowego zaczęto wynagradzać ich deputatami naturaliów. W 1796 roku polecono na rozkaz króla wypłacić członkom królewskim kuratorium po dwa wisple żyta, jęczmienia i owsa na św. Michała ${ }^{32}$.

Kuratorium znajdowało się pod dużo większą kontrolą władz prowincjonalnych i centralnych w Berlinie niż w okresie panowania szwedzkiego. W czasach Fryderyka Wilhelma I decyzje dotyczące szczecińskiego gimnazjum zapadały na ogólnym zebraniu jego ministrów, przede wszystkim tych odpowiedzialnych za sprawy zwierzchności państwowej, w tym Samuela von Cocceji czy Georga Dietloffa von Arnima. W czasach Fryderyka II sprawami Gimnazjum

\footnotetext{
${ }^{27}$ APS, FNMP, sygn. 1441, k. 119-167.

${ }^{28}$ APS, FNMP, sygn. 1441, k. 124, 133-160.

${ }^{29}$ APS, GM, sygn. 6, 9.

${ }^{30}$ APS, FNMP, sygn. 1441, k. 101.

${ }^{31}$ APS, FNMP, sygn. 1441, k. 138-139.

${ }^{32}$ APS, FNMP, sygn. 1441, k. 147.
} 
Akademickiego w Szczecinie zajmował się Departament Duchowny w Berlinie (Departament für Geistliche Angelegenheiten), powiązany z Ministerstwem Sprawiedliwości (Justiz Ministerium) i osobą Wielkiego Kanclerza (Gross Kanzler) - odpowiedzialnego za sprawy sądownictwa, prawa, szkolnictwa oraz religijne. W 1787 roku powołano odrębny urząd centralny dla szkolnictwa - Wyższe Kolegium Szkolne w Berlinie (Oberschulkollegium in Berlin).

Podobnie jak w czasach szwedzkich, kuratorium zajmowało się nadzorem nad fundacją i gimnazjum, ich majątkiem, działalnością szkoły, jej profesorami i uczniami ${ }^{33}$. W 1743 roku król Fryderyk II w rozkazie gabinetowym orzekł, iż Fundacja Mariacka oraz Gimnazjum nadzorowane są przez ustanowione dla nich kuratorium, któremu podlegają administrator, a także prowizor fundacji, podczas gdy pozostałe fundacje pozostawać mają w nadzorze konsystorza ${ }^{34}$.

Egzaminy na profesorów prowadziło kuratorium wspólnie z Rejencją Pomorską, której prezydent, a zarazem pierwszy kurator nominował wybranego kandydata na stanowisko w gimnazjum. Kuratorium wraz z rejencją, a od 1787 roku z utworzonym Prowincjonalnym Kolegium Szkolnym (Provinzial Schul Kolegium) kontrolowali rokrocznie działalność dydaktyczną nauczycieli, a także ich życie pozaszkolne (m.in. moralność). Szkoła musiała co roku przedstawiać kuratorium tzw. listy kondycyjne (Conduiten Liste), które były następnie przekazywane rejencji i kolegium szkolnemu ${ }^{35}$.

Pierwszym zadaniem odbudowanego w 1715 roku kuratorium była wizytacja zakładu. Jej protokół i wnioski zostały przedstawione władzom prowincjonalnym w Stargardzie w marcu 1716 roku. Najważniejszym efektem działania nowego kuratorium było wprowadzenie nowych profesorów na wakujące etaty ustanowiono przede wszystkim nowego rektora, którym został filozof i teolog

\footnotetext{
${ }^{33}$ Kuratorium określało wysokość pensji profesorów i pracowników gimnazjum i fundacji, także wielkość przyznawanych im deputatów (zboże, zwierzęta rzeźne, drób). W 1747 roku dziekan kamieński Ewald von Kleist w imieniu kuratorium wystąpił do ministra i kanclerza Samuela von Cocceji o dodatek 100 tal. dla rektora Quade. W 1730 roku kuratorzy określili wysokość deputatów drewna opałowego dla profesorów, a w 1741 roku wyznaczyli deputat mięsny dla tych ostatnich - po jednym jagnięciu wartości 1 tal. i 4 sgr. oraz jednej gęsi, zob. APS, GM, sygn. 9. Z kolei wobec uczniów Gimnazjum Akademickiego w Szczecinie kuratorzy decydowali o przyznaniu i wysokości stypendiów, zob. APS, GM, sygn. 8.

${ }^{34}$ APS, FNMP, sygn. 1441, k. 21. Wyznaczani przez kuratorium administratorzy fundacji, przysparzali dochodów gospodarując jej majątkiem. W czasach pruskich, tylko w okresie 1715-1732 dochody fundacji wzrosły z 2434 tal. do 7728 tal., a w 1728 roku szkoła i fundacja spłaciły wszystkie zaległe długi z czasów szwedzkich, zob. Gut, ,Szczecińskie”, 71.

35 Tamże, 77.
} 
Michael Friedrich Quade, a także profesorów prawa - Johanna Samuela Heringa oraz retoryki i historii Johanna Bobartha ${ }^{36}$.

Kuratorium opracowywało również kolejne przepisy dla szkoły i fundacji. W 1728 roku opracowano regulamin gimnazjum, który król zatwierdził 23 lutego 1729 roku. Kolejne statuty i regulaminy były przygotowywane w latach 1732 , 1735, 1739, 1742, 1749, 1754, 1763 a także w 1777 i 1788 roku. Przepisy te wprowadzano najczęściej po przeprowadzanych przez kuratorium, a także przedstawicieli władz zwierzchnich, wizytacjach szkoły, podczas których wykazywano liczne niedociągnięcia $\mathrm{w}$ funkcjonowaniu gimnazjum i fundacji, a którym nowe regulacje miały im zaradzici ${ }^{37}$.

Kuratorium Gimnazjum Karolińskiego a także Fundacji Mariackiej w Szczecinie było organem decyzyjnym, nadzorczym i kontrolnym sprawującym pieczę nad ich organizacją i działalnością. Stanowiło reprezentację władcy - fundatora, a także miejscowych elit społecznych, czyli szlachty pomorskiej. W XVIII wieku, za sprawą pruskiej monarchii absolutnej, zakres kompetencji kuratorium był ograniczony przez władze centralne w Berlinie, które najczęściej wydawały ostateczne decyzje w sprawach szkoły czy fundacji. Zmiany w organizacji kuratorium i zakresie jego kompetencji nastąpiły w momencie połączenia gimnazjum akademickiego $\mathrm{z}$ liceum miejskim, a przede wszystkim w momencie reform ustrojowych w Prusach w latach 1807-1815.

\section{Bibliografia}

\section{Źródła niepublikowane}

Archiwum Państwowe w Szczecinie. Fundacja Najświętszej Marii Panny, sygn. 1440, 1441, 1492.

Archiwum Państwowe w Szczecinie. Rękopisy i Spuścizny, sygn. 788.

Archiwum Państwowe w Szczecinie. Gimnazjum Mariackie, sygn. 4, 6, 89.

\section{Źródla publikowane}

Acta Inaugurationis Gymnasii Carolini. Stetini, 1667-1668.

Fons Sapeientiae, Stetini in Gymnasio Carolino ex Dei Gratia Reclusus, Der Weissheit Bruss zu Stettin im Carolinischen Gymnasio auss Gottes Gnade wider eröfnet. Stettin, 1668.

\footnotetext{
${ }^{36}$ APS, FNMP, sygn. 1492.

${ }^{37}$ Wehrmann, „Geschichte”, 103-112; Gut, ,Szczecińskie”, 70-71.
} 


\section{Opracowania}

Fredrich, Carl. „Die ehemalige Marienkirche in Stettin und ihr Besitz”. Cz. 1: Baltische Studien 21 (1918): 143-246; Cz. 2: Baltische Studien 23 (1920): 3-60.

Gaziński, Radosław. „Pedagogium Książęce (lata 1544-1667)”. W: Akademicki Szczecin XVI-XXI wiek, red. Piotr Niedzielski, Waldemar Tarczyński, 15-46. Szczecin, 2016.

Gut, Paweł. „Szczecińskie akademickie szkoły średnie w II połowie XVII i XVIII wieku". W: Akademicki Szczecin XVI-XXI wiek, red. Piotr Niedzielski, Waldemar Tarczyński, 47-80. Szczecin, 2016.

Hasselbach, Karl Friedrich Wilhelm. Der Geschichte des ehemaligen hiesigen Pädagogium, nachherigen K. Gymnasium. Stettin, 1844.

Łukasiewicz, Dariusz. „Państwo brandenbursko-pruskie wobec szkolnictwa na Pomorzu Zachodnim w latach 1648-1806”. W: Szlachta - spoleczeństwo-państwo między Warmia a Rugia w XVIII-XIX wieku, red. Mieczysław Jaroszewicz, Włodzimierz Stępiński, 157-177. Szczecin, 1998.

Łukasiewicz, Dariusz. „Reformy szkolnictwa na Pomorzu Zachodnim w XVIII w.”. Przegląd Historyczny 87 (1996), 3: 515-530.

Mielcarek, Zofia, Bolesław Owczarek. Od Pedagogium do Uniwersytetu Szczecińskiego. Szczecin, 1985.

Oelrichs, Johann Carl Conrad. „Gewechselte Schriften verschiedener grosser Männer vor und wider die ehemahls vorgewesene Verlegung der Universität Greifswald nach Stettin 1666". W: Johann Carl Conrad Oelrichs, Historisch-Diplomatische Beyträge zur litterarischen Geschichte fürnehmblich des Hertzogthums Pommern, 19-31. Cz. 2. Berlin, 1790.

Szultka, Zygmunt. „Ukształtowanie się systemu absolutnego i jego kryzys”. W: Historia Pomorza, red. Gerard Labuda, 787-841. T. 2: cz. 3. Poznań, 2003.

Wachowiak, Bogdan. „Szczecin w okresie przewagi państwa feudalnego (1478-1713)”. W: Dzieje Szczecina, red. Gerard Labuda, 197-443. T. 2: Wiek X-1805. Poznań, 1985.

Wehrmann, Martin. „Geschichte des Marienstifts-Gymnasiums 1544-1894”. W: Festschrift zum dreihundertfünfzigjährigen Jubiläum des Königlichen Marienstifts-Gymnasiums zu Stettin am 24. und 25. September 1894. Stettin, 1894.

Wesołowska, Sylwia. „Das Fürstliche Pedagogium bzw. Gymnasium Carolinum in Stettin”. W: Die Universität Greifswald in der Bildungslandschaft des Ostseeraums, red. Dirk Alvermann, Nils Jörn, Jens E. Olesen, 105-122. Berlin, 2007.

Wiśniewski, Jerzy. „Początki układu kapitalistycznego 1713-1805”. W: Dzieje Szczecina, red. Gerard Labuda, 445-702. T. 2. Poznań, 1985. 


\begin{abstract}
AbstrakT
Powołane w 1667 roku gimnazjum akademickie w Szczecinie kontynuowało tradycje Książęcego Pedagogium. Również wzorem czasów Gryfitów, nadzór nad szkołą oraz fundacją ją finansującą sprawowało czteroosobowe kuratorium, złożone z przedstawicieli administracji prowincjonalnej, a także reprezentantów stanów pomorskich.

Zadania kuratorium określone były w statucie gimnazjum. Zajmowało się ono m.in. majątkiem fundacji i jej dochodami, kontrolowało szkolną administrację, a także zatrudniało profesorów, przyjmowało uczniów do zakładu i nadzorowało proces dydaktyczny W XVIII wieku, w ramach pruskiej monarchii absolutnej, działalność kuratorium ograniczały liczne ingerencje władz centralnych w Berlinie, które najczęściej wydawały ostateczną decyzję w sprawach gimnazjum i Fundacji Mariackiej.
\end{abstract}

\title{
A schoolboard of The Academic Gymnasium in SzCZecin 1667-1805
}

\section{Abstract}

Established in 1667, the Academic Gymnasium in Szczecin was a continuation of the tradition of the princely Pedagogium. Also, like in the Griffins times, the school and the foundation which financed it were supervised by a schoolboard of four persons, comprising the representatives of the province administration and the Pomeranian Estates. The role of the schoolboard was defined in the Gymnasium Statute. It included controlling the administration of the Foundation's estate, its revenues, as well as the administration of the school, employing professors, admitting students to the establishment, supervising them, and supervising the didactic process. In the $18^{\text {th }}$ century, in the framework of the Prussian absolute monarchy, the activity of the schoolboard was limited by the numerous interventions of the central authorities in Berlin, which most often took the final decisions concerning the Gymnasium and the Marian Foundation. 